\title{
Elucidation of the biosynthesis pathway and heterologous construction of a sustainable route for producing umbelliferone
}

\author{
Yucheng Zhao, Xiangyun Jian, Jialin Wu, Wanchun Huang, Chuanlong Huang, Jun Luo* and Lingyi Kong*
}

\begin{abstract}
Background: Coumarins play roles in many biological processes. Angelica decursiva is one of the major sources of coumarins in China. Due to increasing demand for coumarins in the marketplace, traditional extraction from plants is now considered economically insufficient and unsustainable. Microbial synthesis is a promising strategy for scalable production of coumarins. However, the biosynthetic pathway of coumarin remains poorly understood, and even more, the genes associated with this process have not been characterized in A. decursiva.

Results: RNA-seq was employed to elucidate the umbelliferone biosynthetic pathway. The results indicated that three enzymes, phenylalanine ammonia-lyase (PAL), 4-Coumarate: Coenzyme A Ligase (4CL), and p-coumaroyl CoA 2'hydroxylase $\left(\mathrm{C} 2^{\prime} \mathrm{H}\right)$ were involved in umbelliferone biosynthesis. Using the cloned genes, we generated a synthetic biology based microbial cell factory that produces coumarins from tyrosine utilizing Rhodotorula glutinis tyrosine ammonia lyase (RgTAL) to bypass cinnamic acid 4-hydroxylase $(\mathrm{C} 4 \mathrm{H})$. With metabolic engineering strategies, we deleted prephenate dehydratase (pheA), anthranilate synthase (trpE) and transcriptional regulatory protein (tyrR) and overexpressed six related genes involved in tyrosine biosynthesis, to drive the carbon flux from tyrosine. To overcome the limitation of $4 \mathrm{CL}$, a virtual screening and site-specific mutagenesis-based protein engineering approach was applied. In addition, induction/culture conditions and different ions were employed to further improve the yield of umbelliferone. Finally, a yield of $356.59 \mathrm{mg} / \mathrm{L}$ umbelliferone was obtained.
\end{abstract}

Conclusions: The current study elucidated the umbelliferone biosynthesis pathway in A. decursiva. The results also demonstrated the feasibility of integrating gene mining with synthetic biology techniques to produce natural compounds.

Keywords: Coumarins, Biosynthetic pathway, Metabolic engineering, Protein engineering, Synthetic biology

\section{Background}

Coumarin, which has a 2H-1-benzopyran-2-one core structure, is widely distributed in the Umbelliferae, Fabaceae, Rosaceae, Rutaceae, and Saxifragaceae [1]. Apart from their role in environmental adaptation, coumarin derivatives have also been demonstrated to have anti-inflammatory, anticancer, antioxidant, and anti-hyperglycaemic activities [2-6]. Hence, securing the supplies of these compounds

\footnotetext{
*Correspondence: luojun1981ly@163.com; cpu_lykong@126.com Jiangsu Key Laboratory of Bioactive Natural Product Research and State Key Laboratory of Natural Medicines, School of Traditional Chinese Pharmacy, China Pharmaceutical University, Nanjing 210009, People's Republic of China
}

from medicinal plants has been a long-standing practice. $A$. decursiva is one of the main sources of coumarins in China and is listed as a special coumarin resource in the current Pharmacopeia of China [7]. However, low abundance and season- or region-dependent sourcing limit its widespread application. Producing coumarin via solvent extraction or soil excavation is considered harmful to the environment $[8,9]$. In addition, the complexity and multiple chiral centers of these compounds limit their production via industrial de novo chemical synthesis [10]. Owing to these issues, pharmaceutical companies and scientists are seeking alternative methods. An economical and environmentally

(c) The Author(s). 2019 Open Access This article is distributed under the terms of the Creative Commons Attribution 4.0 International License (http://creativecommons.org/licenses/by/4.0/), which permits unrestricted use, distribution, and 
friendly production platform and/or approach appear to be urgently needed.

The use of engineered microorganisms in metabolic engineering is rapidly emerging as a promising biotechnological technique for resolving these issues. With this technology, it is possible to design and reconstruct a synthetic route in microorganisms for producing natural products [11-13]. A comprehensive understanding of structural and biochemical properties of enzymes involved in natural product biosynthesis is a prerequisite for using such methods. However, the coumarin biosynthetic pathway has not yet been completely resolved. Even more, genes associated with coumarin biosynthesis have not been cloned in $A$. decursiva. The rapidity and efficiency of gene discovery has improved dramatically, due to advances in next-generation sequencing technology (NGS), such as Roche/454 and Illumina HiSeq platforms, and annotation information available in public databases such as the National Center for Biotechnology Information (NCBI) [14, 15]. Hence, we could use RNA-seq data to identify the genes involved in coumarins biosynthesis and construct a microbial cell factory to produce umbelliferone for it formed the core structure of other kinds of coumarins [3]. However, issues such as low yield and the high cost of precursor chemicals associated with this approach make it commercially unfeasible $[16,17]$. Hence, systematic construction of a sustainable route for large scale production compound using inexpensive and readily available materials is a challenge that needs to be addressed [18].

Among strategies used for successful development of industrial microbial strains, enzyme selection, pathway optimization/reconstruction, and cofactor/precursor availability are considered to be most important [18]. In enzyme selection, choosing candidate enzymes which facilitate the completion of a target route spans the traditional scope of consideration. However, refining the catalytic efficiency of target enzymes via enzyme and protein engineering is also needed [19]. In pathway optimization/reconstruction, the overall project design, host strain selection, rerouting and optimization of metabolic fluxes, optimization of microbial culture conditions and scale-up fermentation need to be considered. However, most work merely focuses on the design of a metabolic pathway to produce target compounds (for example, alkaloid-based drugs), and little attention is paid to systematic robustness of the pathway or its synthetic ability to improve the yield of compounds [20]. In addition, the two-step culture process and the tyrosine/precursor supplement may substantially limit large-scale production of metabolites via fermentation [21]. Hence, systematic improvement of precursor supplies and pathway robustness may further enhance the yield of target compounds (for example, flavonoids) [21].

In this study, RNA-seq dataset and functional verification were initially employed to elucidate the umbelliferone biosynthetic pathway. Next, the genes involved in umbelliferone biosynthesis were constructed in prokaryotic expression vectors and introduced into Escherichia coli to produce the umbelliferone. In this process, gene knockout and overexpression were conducted to construct a L-tyrosine platform to ensure precursor supplementation. In order to bypass the 4CL limitation, virtual screening and site-specific mutagenesis-based protein engineering were applied. In addition, systematic optimization, specifically of medium, induction and culture conditions and the addition of different ions were employed to further improve the yield of umbelliferone. Finally, a total umbelliferone concentration of $356.59 \mathrm{mg} / \mathrm{L}$ was obtained. In summary, we elucidated the coumarin biosynthesis pathway and conducted heterologous construction of a sustainable route for umbelliferone production. The study also indicated that a combination of metabolic pathway optimization and protein engineering may be effective in producing umbelliferone.

\section{Results \\ Candidate gene mining using transcriptome sequencing and similarity search}

To mine candidate genes involved in the umbelliferone biosynthesis, the transcriptome dataset of the A. decursiva was constructed for the first time (NCBI accession number PRJNA360870), due to the absence of information on genes related to A. decursiva. This produced approximately 49 million clean reads and 139,956 unigenes (194,616 contigs) with a mean length of $639 \mathrm{nt}$ and a N50 of $1309 \mathrm{nt}$ following de novo assembly (Fig. 1). Considering that pyranocoumarins, which originating from umbelliferone, are the main chemical constituents of $A$. decursiva, its biosynthetic mechanism was estimated according to previous reports (Fig. 1) [3, 22, 23]. Although there are no reports on the complete biosynthesis mechanism of umbelliferone, the proposed pathway, which had been functionally appraised at each step previously in other plants, seems irrefutable [24-26]. As shown in Fig. 1, the umbelliferone biosynthesis pathway was initiated by PAL, following which $\mathrm{C} 4 \mathrm{H}$ was employed to yield $p$-coumaric acid [24]. Afterwards, 4CL was needed to produce $p$-coumaric CoA, that may be used as an intermediate to produce various compounds.

(lignin, flavones, and coumarins) [26]. Of these compounds, coumarins are produced by the formation of umbelliferone via C2'H. Next, a local BLAST search was performed to identify candidate genes involved in umbelliferone biosynthesis from our transcriptome dataset. The templates used for local BLAST search (Table 1) were from Umbelliferae plant Peucedanum praeruptorum (PpPAL, $\left.\mathrm{Pp} 4 \mathrm{CL}, \mathrm{PpC2}{ }^{\prime} \mathrm{H}\right)$, Angelica sinensis (AsPAL), Petroselinum crispum (PcC4H, Pc4CL1), Angelica gigas $(\mathrm{AgC} 4 \mathrm{H})$ and Pastinaca sativa $\left(\mathrm{PsC}^{\prime} \mathrm{H}\right)$. And they were all functionally 


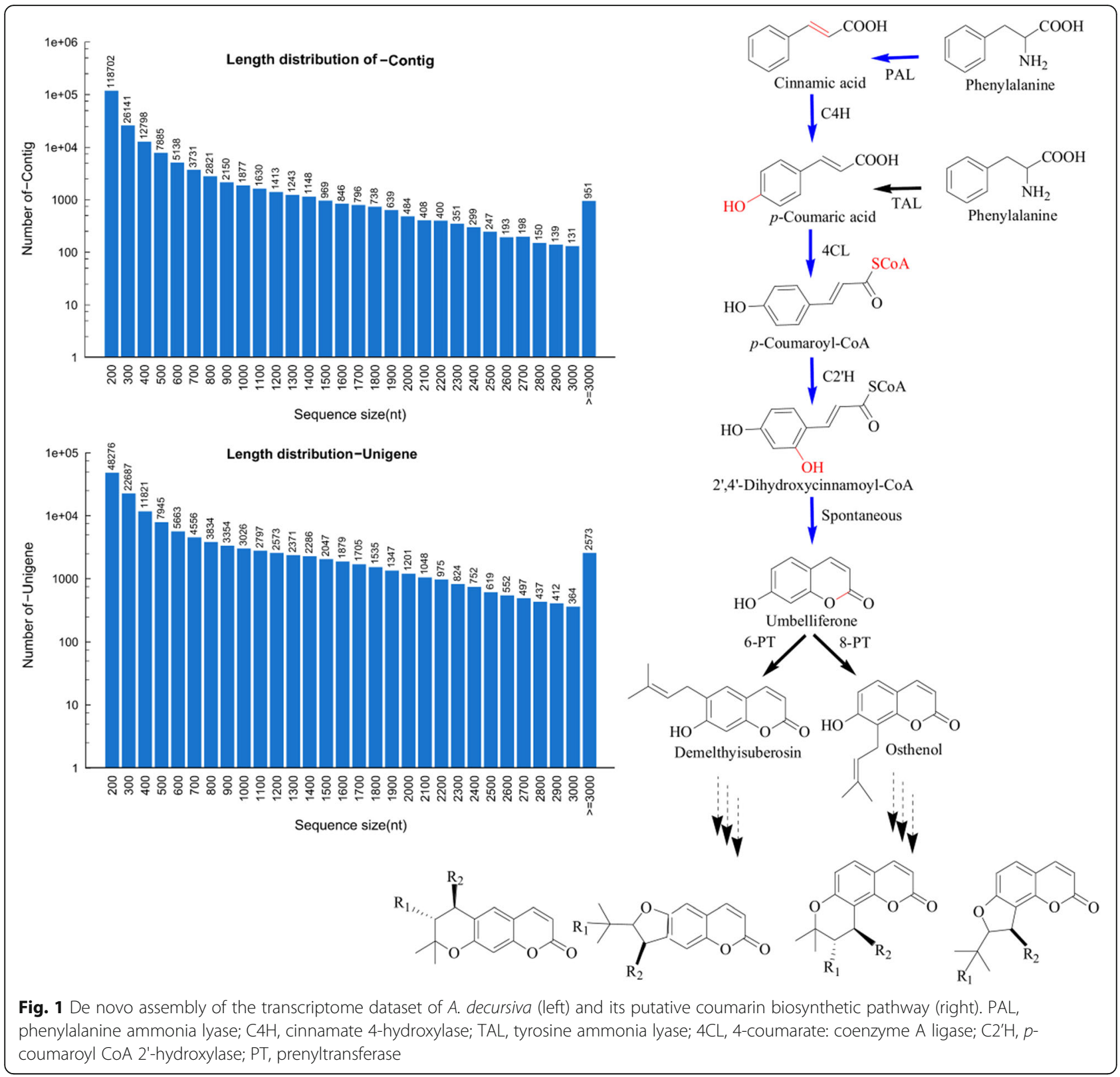

confirmed [25-27]. According to the identities and E-Values of the BLAST results, 13.

unigenes/transcripts were selected as candidates, 7 of which may be true candidates (Table 1). For example, Unigene23067 (or Unigene23068) has 100\% identity with $P c C 4 H$ in amino acids $1-269$ (or 269-505 in Unigene23067), indicating that it may encode a candidate $\mathrm{C} 4 \mathrm{H}$ in $A$. decursiva. However, Unigene 24470 is not the target gene for it has a low identity to the template (33\%, Table 1). CL2481.Contig2/Unigene35034 were completely aligned to $P p C 2^{\prime} H / P p 4 C L$, and Unigene23067/23068 could be linked to a single gene for which we obtained the full-length coding sequence (CDS) (Table 1).

\section{Functional characterization of the candidate genes}

To determine their function, deduced full-length CDSs of $A d C 4 H, A d 4 C L, A d C 2 ' H$ and the rapid amplification of cDNA ends (RACE) product of $A d P A L$ were amplified from $A$. decursiva cDNA. Following sequencing, the genes were introduced into pET28a under the T7 promoter and 6"His tag. Then, the proteins were expressed and purified for enzymatic activity on their target substrates. As a result, all enzymes except $\mathrm{C} 4 \mathrm{H}$ readily yielded additional peaks corresponding to their expected products (Fig. 2). The data indicated that the selected genes were indeed the target genes involved in umbelliferone biosynthesis. Although its activity was not resolved, we propose that Unigene $23067 / 23068$ is the true $C 4 H$ because there is only 
Table 1 The candidate genes involved in umbelliferone biosynthesis

\begin{tabular}{|c|c|c|c|c|c|c|c|}
\hline Gene name & Template name (accession number) & Gene ID & Size & Score & E- Value & Identities & CDS \\
\hline \multirow[t]{4}{*}{ PAL } & \multirow[t]{4}{*}{ PpPAL (AYJ76815)/AsPAL (AJW77399) } & CL5684.Contig2 & 2445 & 1347 & 0.0 & 95 & $7-719$ \\
\hline & & CL5684.Contig1 & 1510 & 950 & 0.0 & 95 & 159-661 \\
\hline & & CL5684.Contig3 & 491 & 307 & $2 e-83$ & 95 & 138-303 \\
\hline & & Unigene17753 & 555 & 281 & $2 e-75$ & 73 & $540-719$ \\
\hline \multirow[t]{3}{*}{$\mathrm{C} 4 \mathrm{H}$} & \multirow[t]{3}{*}{ PcC4H(Q43033)/ AgC4H(AEA72281) } & Unigene23067 & 973 & 539 & e-153 & $100 \%$ & $1-269$ \\
\hline & & Unigene23068 & 849 & 486 & e-137 & $100 \%$ & $269-505$ \\
\hline & & Unigene24470 & 1667 & 265 & $8 e-71$ & $33 \%$ & $18-486$ \\
\hline \multirow[t]{3}{*}{$4 C L$} & \multirow[t]{3}{*}{ Pp4CL(APU52013)/ Pc4CL1(P14913) } & Unigene35034 & 2074 & 1053 & 0.0 & $97 \%$ & $1-543$ \\
\hline & & Unigene34377 & 1892 & 934 & 0.0 & $84 \%$ & $8-543$ \\
\hline & & Unigene33668 & 1969 & 339 & $5 e-93$ & $37 \%$ & $12-532$ \\
\hline \multirow[t]{3}{*}{$\mathrm{C}^{\prime} \mathrm{H}$} & \multirow[t]{3}{*}{ PpC2'H (ASR80916)/ PsC2'H (APP94171) } & CL2481.Contig2 & 1315 & 701 & 0.0 & 98 & $1-350$ \\
\hline & & CL2481.Contig1 & 800 & 368 & e-102 & 75 & $1-236$ \\
\hline & & Unigene29914 & 1083 & 296 & $2 \mathrm{e}-80$ & 44 & $1-330$ \\
\hline
\end{tabular}

one $\mathrm{C} 4 \mathrm{H}$ transcript in the transcriptome dataset. In addition, nearly $100 \%$ identity with $\mathrm{PcC} 4 \mathrm{H}$ also indicated that it encode $A d C 4 H$. Functional expression of CYP450s in prokaryotes, such as $E$. coli, is difficult due to the absence of compartmentalized organelles and membrane structure, and the fact that electrons cannot be supplied from reduced coenzyme II [28]. Hence, additional peak was not observed, and other expression systems, such as yeast, may be needed to further $\mathrm{C} 4 \mathrm{H}$ expression. Finally, the 4 genes were submitted to NCBI with the accession numbers of MK350248, MK350249, MK350250 and MK350251 for AdPAL, AdC4H, Ad4CL and AdC2'H, respectively.

\section{Heterologous construction of a synthetic biology route for umbelliferone production}

Umbelliferone, which is a processed product of coumarin biosynthesis, is difficult to trace because it may be converted by prenyltransferase or other downstream enzymes to produce umbelliferone derivatives (Fig. 1) [29-31]. Hence, using the genes obtained from our transcriptome dataset, a synthetic biology route was heterologous constructed to produce umbelliferone. Considering $\mathrm{C} 4 \mathrm{H}$ expression in prokaryotes is difficult, RgTAL was selected to produce umbelliferone for it is able to bypass the hydroxylation step to produce $p$-coumaric acid (Fig. 1b) [32]. Eventually, $\operatorname{RgTAL}, A d 4 C L$ and $A d C 2 ' H$ were cloned into prokaryotic expression vector according to the protocol for $\mathrm{pCDF}$ design in materials and methods part. As expected, a signal main peak was observed in the fermentation broth which was identified as umbelliferone (Fig. 3). However, we did not find any trace of $p$-coumaroyl-CoA, which is in accordance with most publications [32, 33]. The results indicated that $4 \mathrm{CL}$ may be the limiting factor for a high umbelliferone yield. In addition, the low yield and the requirement for additional L-tyrosine limited its industrial production. With the construction of a synthetic biology route for umbelliferone production accomplished, the next challenge would be to develop methods to improve the yield of umbelliferone using a raw carbon source.

\section{Construction of a tyrosine high-producing platform}

To systematically improve the robustness of the synthetic pathway performance, a tyrosine high-producing platform was constructed. As depicted in Additional file 1: Figure S1, rational modular engineering included the 3-deoxy-arabin oheptulosonate-7-phosphate (DAHP) module, chorismate (CHA) module and tyrosine module. In the DAHP module, transketolase $(t k t A)$ was overexpressed to improve the metabolic flux of erythrose 4-phosphate (E-4-P), and the feedback resistant mutant DAHP synthase $\left(\right.$ aro $G^{f b r}$ ) was simultaneously overexpressed to synthesize DAHP with E-4-P [34]. In CHA module, dehydroquinate synthase, shikimate dehydrogenase, and shikimate kinase I (aroB, aroE and aroK) were placed in a single DNA fragment. However, each had an independent T7 and RBS sequences (pRSF) to improve the metabolic flux of DHAP into CHA $[35,36]$. Studies have indicated that tyrR protein may suppress the expression of genes involved in aromatic amino-acid biosynthesis [37], and the tyrR was deleted from the genomic DNA of E. coli. In the tyrosine module, overexpressing the feedback-resistant mutant of (chorismate mutase/prephenate dehydrogenase) tyrA could enhance the accumulation of L-tyrosine, and knocking out pheA and trpE may reduce the loss of metabolic flux of CHA [34, 38]. Overexpression of $\operatorname{tyr} A^{f b r}$ and knock out of pheA and $\operatorname{trp} E$ was conducted to improve the potentially improve the high yield of tyrosine. Generally, after gene knockout and overexpression, six strains were obtained to analyze their ability in producing 


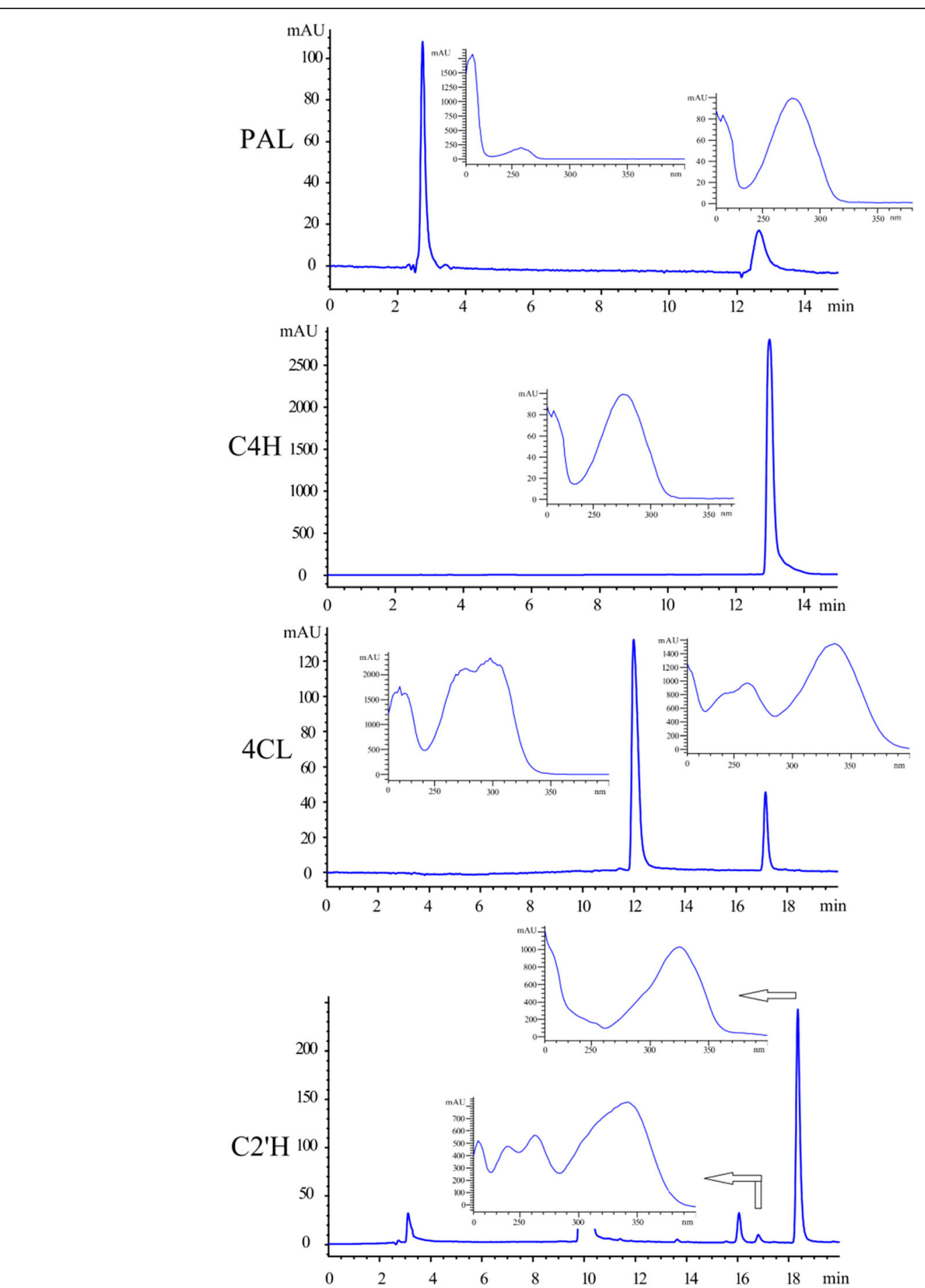

Fig. 2 Enzymatic characteristics of AdPAL, AdC4H, Ad4CL and AdC2'H expressed in E. coli. Ultraviolet absorption spectra of substrates and their products are also shown beside the corresponding peak

tyrosine (Table 2). The results indicate that a single knockout may not improve tyrosine yield. However, when tyrR was deleted, a clear improvement in the yield of tyrosine, approximately 6 times increase, was observed (Table 2). However, there was also a trend towards deleting genes that somewhat influenced bacterial growth, and a decreasing absorbance was observed. Hence, a triple knockout strain was used due to its high capacity for tyrosine synthesis (PET, Table 3). To analyze the ability of different strains to produce the umbelliferone, $\mathrm{pCDF}$ was introduced into the different strains. As indicated in Fig. 4, the strain knocking out pheA, trpE, tyrR and overexpressing pRSF (PET-pRSF) 


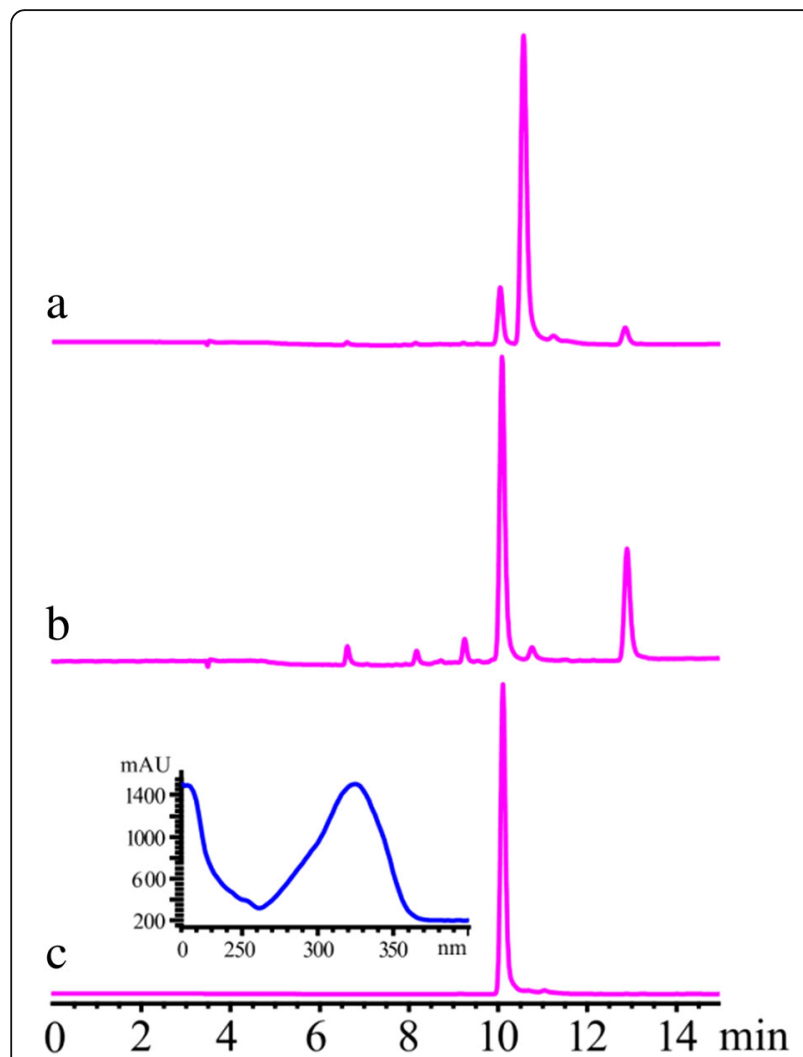

Fig. 3 Heterologous construction of a synthetic biology route for umbelliferone production. (a), The first attempt at heterologous construction of a synthetic biology route for umbelliferone production; (b), umbelliferone production with the optimized conditions; (c), umbelliferone standard

produced the highest umbelliferone, conforming to the tyrosine yield in Table 2 .

\section{Selection of enzyme sources and evolution of $4 \mathrm{CL}$ with protein engineering}

In this study, a virtual screening strategy was used to select or optimize the enzyme with potential for product improvement. Based on the report that TAL from the red yeast, $R$. glutinis, showed the highest activity, compared with 7 other bacterial and fungal TAL enzymes, it was used to produce $p$-coumaric acid [39]. As 4CL activity appears to play a crucial role in compound

Table 2 Effects of gene knockout and overexpress on the production of tyrosine

\begin{tabular}{llll}
\hline Strains & Growth $\left(\mathrm{OD}_{600} / 24 \mathrm{~h}\right)$ & L-tyrosine $(\mathrm{mg} / \mathrm{L})$ & Tyrosine/OD ratio \\
\hline K12 & $1.86 \pm 0.01$ & $21.2 \pm 0.1$ & 11.3 \\
$\mathrm{P}$ & $1.41 \pm 0.00$ & $29.3 \pm 0.1$ & 20.8 \\
$\mathrm{E}$ & $1.39 \pm 0.06$ & $26.6 \pm 0.1$ & 19.1 \\
$\mathrm{PE}$ & $1.53 \pm 0.03$ & $61.1 \pm 0.3$ & 39.9 \\
PET & $1.08 \pm 0.05$ & $93.0 \pm 0.2$ & 86.1 \\
PET-PRSF & $1.16 \pm 0.03$ & $118.4 \pm 0.4$ & 102.1 \\
\hline
\end{tabular}

production (Fig. 3), we next focused on how to select a suitable $4 \mathrm{CL}$ to convert $p$-coumaric acid. As there are only a few reports on 4CL selection, virtual screening and site-specific mutagenesis were used to select a candidate 4CL which efficiently produces umbelliferone. Firstly, eighteen 4CLs from different sources were virtually screened and sorted according to their estimated binding energies (Fig. 5). Then, four 4CLs showing potential for better.umbelliferone production were synthetized or PCR cloned, and used for expressing 4CL proteins. As indicated in Fig. 6a, 4CL1 from P. crispum tended to show a better performance in producing umbelliferone, despite ranking second compared with other 4CLs in our virtual screening. To further improve the yield of umbelliferone, a site-specific mutagenesisbased protein engineering approach was employed according to the directed evolution results of Lycopersicon esculentum 4CL (Le4CL) and the protein structure of Pt4CL [40, 41]. For instance, in Le4CL, V186G and F239S could improve the activity of Le4CL toward p-coumaric acid. Accordingly, the corresponding mutations of V184G, Q272H, F267 L, and so on, were generated in our target Pc4CL according to the sequence alignment results of Pc4CL, Le4CL and Pt4CL (Additional file 1: Figure S3). As indicated in Fig. 6b, the double mutant of Q272H and F267 L seemed play an important role in the good positive activity of $4 \mathrm{CL}$. Hence, 4CL with Q272H and F267 L was used to produce compounds (PET-pRSF-Pc4CL1-M).

\section{Optimization of fermentation conditions to enhance umbelliferone production}

Optimization of fermentation conditions was conducted to further enhance umbelliferone production. Considering that ions were also reported to affect the yield of gamma-aminobutyric acid [42], the effects of $\mathrm{FeSO}_{4}$, $\mathrm{FeCl}_{3}, \mathrm{CaCl}_{2}, \mathrm{MgCl}_{2}, \mathrm{ZnSO}_{4}, \mathrm{CuSO}_{4}, \mathrm{MnSO}_{4}, \mathrm{CoCl}_{2}$, $\mathrm{NiCl}_{2}, \mathrm{LiAc}$ and $\mathrm{Na}_{2} \mathrm{MoO}_{4}$ were investigated at concentration of 50,100 and $500 \mathrm{mg} / \mathrm{L}$ were also investigated. As indicated in Additional file 1: Table $\mathrm{S} 1, \mathrm{Mn}^{2+}$ at a concentration of $100 \mathrm{mg} / \mathrm{L}$ positively enhanced the production of umbelliferone, where $\mathrm{Co}^{2+}$ played an inhibitory role. In addition, the inductor concentration $(1,10,100$, $1000 \mu \mathrm{M})$, induction temperature $\left(15,20,25,30,35^{\circ} \mathrm{C}\right)$ and induction time $(5,10,15,20,25 \mathrm{~h})$ were also investigated (Additional file 1: Table S2). Results indicated that while lactose at a concentration of $100 \mu \mathrm{M}$ had the same effect as isopropyl $\beta$-D-thiogalactoside (IPTG), a low induction temperature and a high conversion temperature were favorable for enhancing the yield of products. Hence, ultimately, a conversion temperature of $40^{\circ} \mathrm{C}$, a lactose concentration of $100 \mu \mathrm{M}$ and an induction temperature of $15^{\circ} \mathrm{C}$ with an induction time of $5 \mathrm{~h}$ were used to further improve umbelliferone yield. Along with the selected 
Table 3 Strains and plasmids used and constructed in this study

\begin{tabular}{|c|c|c|}
\hline & Description & Source \\
\hline \multicolumn{3}{|l|}{ Strains } \\
\hline E.coli DH5a & General cloning host & Invitrogen \\
\hline E. coli K12 (MG1655) & $F-, \lambda$-, ilvG-, rfb-50, rph-1 & Novagen \\
\hline E.coli BL21(DE3) & F-, ompT, hsdS $\left(\mathrm{r}_{\mathrm{B}}^{-} \mathrm{m}_{\mathrm{B}}^{-}\right)$, gal, dcm (DE3) & Novagen \\
\hline $\mathrm{K} 12$ & E. coli $\mathrm{K} 12$ carrying the gene for T7 RNA polymerase in pGEX6P-1 & This study \\
\hline$P$ & $\mathrm{~K} 12 \Delta p h e A$ & This study \\
\hline E & $\mathrm{K} 12 \Delta \operatorname{trp} E$ & This study \\
\hline PE & $\mathrm{K} 12 \Delta p h e A \Delta \operatorname{trp} E$ & This study \\
\hline PET & $\mathrm{K} 12 \Delta p h e A \Delta \operatorname{trp} E \Delta t y r R$ & This study \\
\hline PET-pRSF & PET carrying pRSF & This study \\
\hline K12-pCDF & K12 carrying pCDF & This study \\
\hline P-pCDF & P carrying pCDF & This study \\
\hline E-pCDF & E carrying pCDF & This study \\
\hline PE-pCDF & PE carrying $p C D F$ & This study \\
\hline PET-pCDF & PET carrying pCDF & This study \\
\hline PET-pRSF-pCDF & PET-pRSF carrying pCDF & This study \\
\hline PET-pRSF-Pc4CL1 & PET-pRSF carrying pCDF-Pc4CL1 & This study \\
\hline PET-pRSF-Pt4CL & PET-pRSF carrying pCDF-Pt4CL & This study \\
\hline PET-pRSF-At4CL1 & PET-pRSF carrying pCDF-At4CL1 & This study \\
\hline PET-pRSF-At4CL2 & PET-pRSF carrying pCDF-At4CL2 & This study \\
\hline PET-pRSF-Pc4CL1-M & PET-pRSF carrying pCDF-Pc4CL1 (Q272H/F267 L) & This study \\
\hline \multicolumn{3}{|l|}{ Plasmids } \\
\hline pET28a & T7 promoters, pBR322 ori, $\mathrm{Kn}^{\mathrm{R}}$ & Novagen \\
\hline pRSFDuet-1 & Double T7 promoters, RSF ori, $\mathrm{Kn}^{\mathrm{R}}$ & Novagen \\
\hline pCDFDuet-1 & Double $T 7$ promoters, CloDF13 ori, Sm & Novagen \\
\hline pRSF-1 & pRSFDuet-1 carrying tktA & This study \\
\hline pRSF-2 & pRSFDuet-1 carrying $t k t A$, aro $B$, aro $E$ and aro $K$ & This study \\
\hline pRSF & pRSFDuet-1 carrying $t k t A$, aro $G^{f b r}$, $t y r A^{f b r}$, aroB, aro $E$ and aroK & This study \\
\hline pCDF-1 & pCDFDuet-1 carrying RgTAL & This study \\
\hline pCDF-2 & pCDFDuet-1 carrying RgTAL, Ad4CL & This study \\
\hline pCDF & pCDFDuet-1 carrying RgTAL, Ad4CL, AdC2'H & This study \\
\hline pCDF-PC4CL1 & pCDFDuet-1 carrying RgTAL, PC4CLI, AdC2'H & This study \\
\hline pCDF-Pt4CL & pCDFDuet-1 carrying RgTAL, Pt4CL, AdC2'H & This study \\
\hline pCDF-At4CL1 & pCDFDuet- 1 carrying RgTAL, At4CL1, AdC2'H & This study \\
\hline pCDF-At4CL2 & pCDFDuet-1 carrying RgTAL, At4CL2, AdC2'H & This study \\
\hline
\end{tabular}

strain and enzyme, an umbelliferone yield of $356.59 \mathrm{mg} / \mathrm{L}$ was obtained.

\section{Discussion}

According to the compound structure identified from $A$. decursiva, we could partially estimate the biosynthetic mechanism of coumarin, despite the biosynthetic pathway of coumarins has not been completely investigated and no one gene has ever been reported in $A$. decursiva $[3,23]$. As indicated in Fig. 1, at least four genes are involved in the biosynthesis of the coumarin skeleton. Considering that genes such as $P A L, C 4 H, 4 C L$ and $C 2$ ' $H$ from other species had been recently identified, we used the similarity search method to detect the corresponding candidate enzymes possibly involved in $A$. decursiva coumarin biosynthesis [24-26]. However, genomic data is unavailable at present. Due to NGS technology and annotation information available in NCBI, rapidity, and efficiency of gene discovery has improved dramatically $[14,15]$. Hence, at the beginning of this study, we constructed the transcriptome 


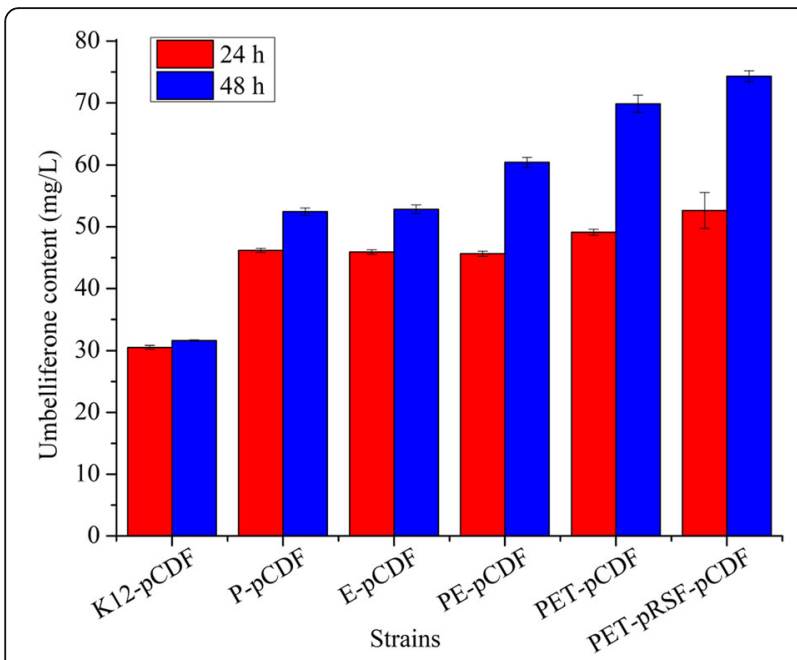

Fig. 4 Comparison of different strains for the production of umbelliferone. Red and blue bars represent the umbelliferone concentration in $24 \mathrm{~h}$ and $48 \mathrm{~h}$, respectively. The characteristics of different strains used in this experiment are listed in Table 3. All data are represented as mean \pm SD from three independent experiments $(n=3)$. Error bars are defined as SD dataset of $A$. decursiva. Next, a local BLAST search was conducted to predict candidate genes. As shown in Table 1 , most genes have a high similarity to their template, indicating that candidate genes may serve the same function as known template genes. To confirm the genes functionally, we tested the function of all candidate genes in vitro, and the results indicated that all genes except $\mathrm{C} 4 \mathrm{H}$ had corresponding functions (Fig. 2). Therefore, the umbelliferone biosynthesis in $A$. decursiva was established for the first time.

Considering that umbelliferone is an intermediate product of coumarin biosynthesis, an insufficient amount of umbelliferone can be accumulated in plants [23]. In addition, umbelliferone is a compound with biological activity and also acts as a precursor compound to produce various coumarin derivatives [31, 43, 44]. Hence, obtaining umbelliferone is urgent. Although many reports have been published on microbial production of secondary metabolites from glucose or mesostates, only a few focused on systematically improving target compound yields, and low yield makes these processes unfit for use under industrial conditions [16, 17, 45, 46]. In this study, we identified all genes involved in umbelliferone biosynthesis in A. decursiva, and re-structured its biosynthesis in vitro. The yields observed in our initial

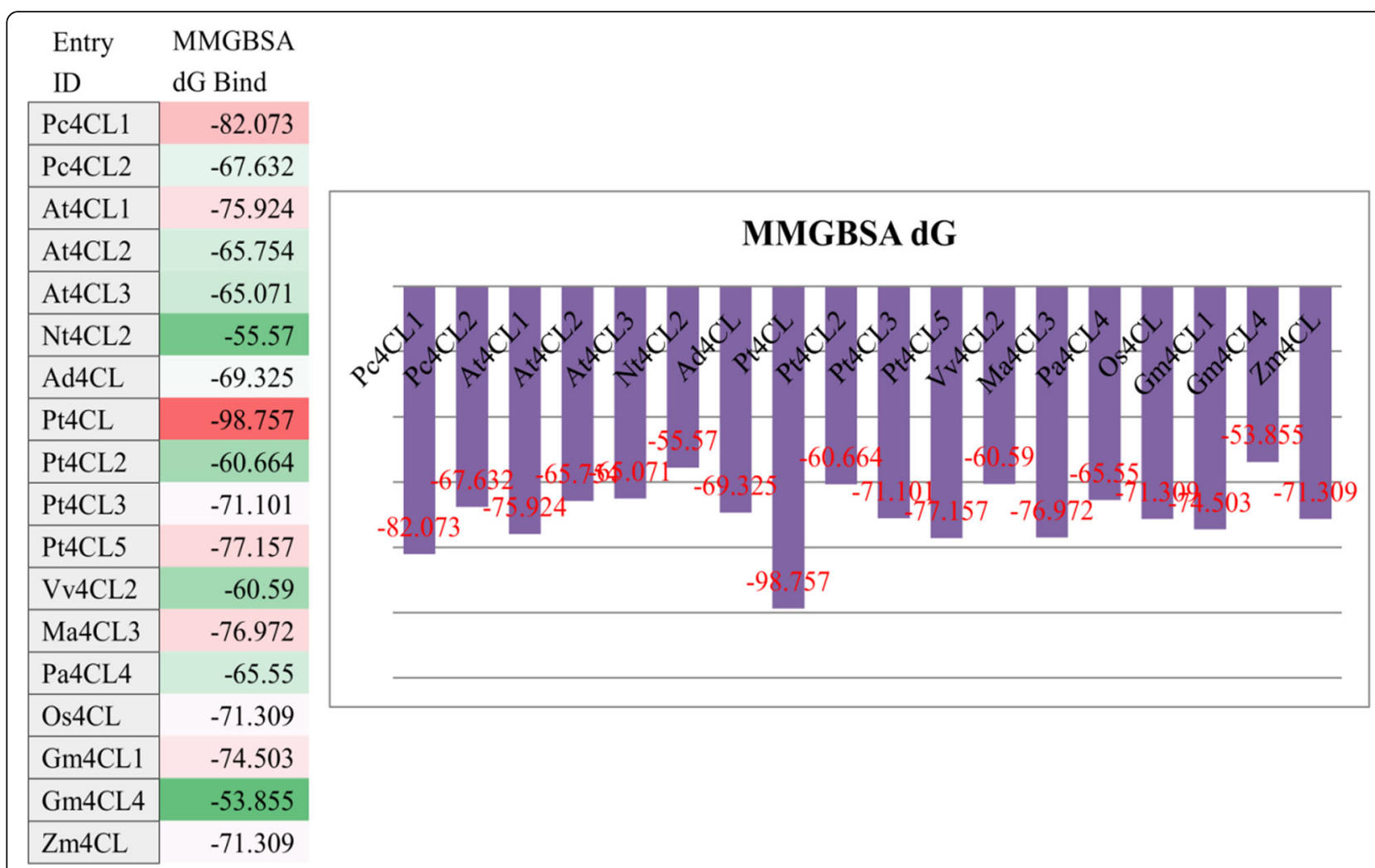

Fig. 5 Virtual screening of different $4 C L$ s using estimated binding energies (MM/GBSA dG) to adenosine $5^{\prime}$-coumaroyl phosphate. The different $4 C L s$ estimated binding energies are listed on the left and are also drawn on the right 

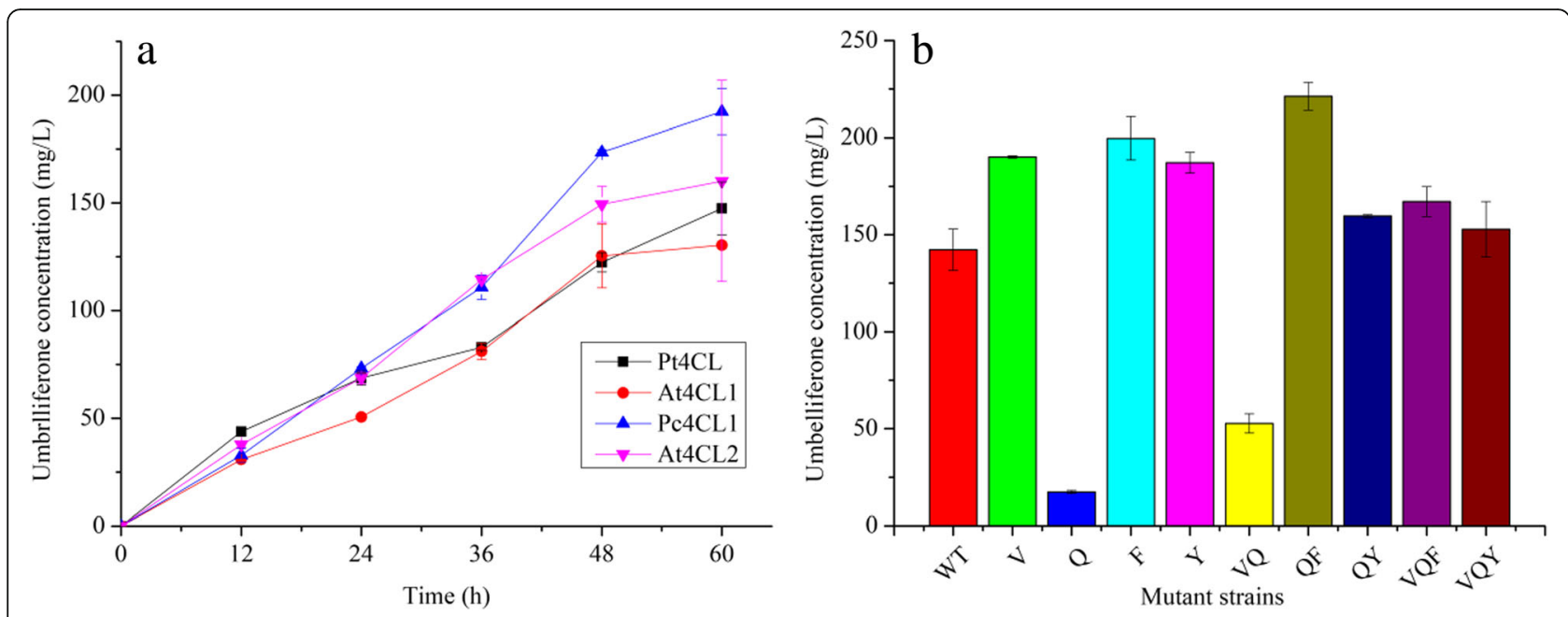

Fig. 6 Umbelliferone production with different 4CLs and PC4CL1 with different mutants. (a), The yield of umbelliferone in different strains expressing different $4 \mathrm{CLs}$ was measured for $60 \mathrm{~h}$ at $12 \mathrm{~h}$ increments. (b), The yield of umbelliferone with different PC4CL1 mutations was measured at 48 h. V, Q, F, Y, VQ, QF, QY, VQF, VQY denotes Pc4CL1 V184G, Q272H, F267 L, Y240A, V184G/Q272H, Q272H/F267 L, Q272H/Y240A, V184G/Q272H/F267 L, V184G/Q272H/ Y240A mutations, respectively. All data are represented as mean \pm SD from three independent experiments $(n=3)$. Error bars are defined as SD

experiments were also low (Fig. 3). To improve candidate compound yield, a systematic strategy, consisting of integration of metabolic engineering and protein engineering, was conducted in engineered bacteria.

Considering that shikimate or tyrosine serves as the main precursor for the biosynthesis of phenylpropanoid compounds, we focused on the development of a microorganism platform with an enhanced capacity for shikimate/tyrosine production according to a previous report $[34,45]$. Elimination of the bypass pathway and feedback inhibition was first conducted to reinforce tyrosine yield. Results indicated that simultaneous deletion of the tryptophan and phenylalanine bypass pathway could significantly enhance tyrosine yield (Table 2 ). Despite reports that overexpression of the genes involved in E-4-P, CHA and tyrosine biosynthesis may improve the final output of tyrosine, the effects were not as significant, in our experiment [34-36]. In contrast, deletion of tyrR from the genomic DNA of E. coli resulted in a considerable tyrosine yield. This phenomenon may be interpreted as being due to deletion of tyrR resulting in the inhibition of gene expression suppression involved in tyrosine biosynthesis [37]. Hence, a strain with null pheA, trpE and tyrR (PET) was used to produce tyrosine.

Development of precursor producing platforms to improve the yield of target compounds is somewhat effective, but it is often limited by the activity level of the downstream enzyme. A previous study has indicated that enzymes from different sources may affect the yield of products differently, and thus, selecting enzymes from different sources may provide an alternative way to further improve product yields. However, most researchers have focused on comparing enzymes from different sources, and little has been reported on improving enzyme performance in nature $[19,21]$. In this study, a virtual screening strategy was conducted to select or optimize the enzymes with potential for product improvement. The work mainly focused on selecting a suitable $4 \mathrm{CL}$ to convert $p$-coumaric acid because $p$-coumaric acid can be copiously produced by RgTAL [39]. We first selected eighteen 4CLs for virtual screening using the $\mathrm{mm} / \mathrm{gbsa}$ method by Prime (Prime, Schrödinger) [47]. Based on the estimated binding energies (Fig. 5 ), four 4CLs were selected to test for umbelliferone production ability. Based on the yield (Fig. 6), 4CL from $P$. crispum was used for site-specific mutagenesis according to the directed evolution results of Le4CL (Additional file 1: Figure S2) [40, 41]. The results indicated that double mutation of Q272H and F267 L may improve the yield of umbelliferone.

Actually, optimization of fermentation conditions could further improve the production of candidate compound despite there are little reports focused on this method [48]. Therefore, fermentation conditions together with induction conditions were optimized to further enhance umbelliferone yield. The effect of ions on the yield of umbelliferone was first investigated. Results indicated that $\mathrm{Mn}^{2+}$ may enhance umbelliferone production, which is in accordance with previous reports (Additional file 1: Table S1) [42]. Inductor concentration, induction time and induction temperature were also investigated (Additional file 1: Table S2). Considering economic factors, a conversion temperature of $4{ }^{\circ} \mathrm{C}$, a lactose concentration of $100 \mu \mathrm{M}$, an induction temperature of 
$15^{\circ} \mathrm{C}$, and induction time of $5 \mathrm{~h}$, are recommended for further improving umbelliferone yield. Although not much research has been conducted on optimization of fermentation conditions, our results indicated that optimizing fermentation conditions may significantly improve the yield of products.

\section{Conclusions}

In this study, the RNA-seq dataset and the umbelliferone biosynthetic pathway in $A$. decursiva were elucidated for the first time. Furthermore, the genes involved in umbelliferone biosynthesis were introduced into microbial cells to produce umbelliferone. Metabolic as well as protein engineering was conducted to enhance umbelliferone yields. We used the gene knockout PET-pRSF strain, containing the Q272H and F267 L double mutation of Pc4CL1, to produce umbelliferone. Under optimized fermentation conditions, an umbelliferone yield of 356.59 $\mathrm{mg} / \mathrm{L}$ was obtained. These findings proved that a combination of metabolic pathway optimization and protein engineering is useful in producing umbelliferone.

\section{Materials and methods}

\section{Strains, plasmids and chemicals}

Generally, E. coli DH5 $\alpha$ was employed as the host for plasmid amplification and gene cloning. E. coli BL21 (DE3) and K12 (with T7-RNA polymerase) were used for recombinant protein expression, enzyme assays, and fermentation experiments. Unless otherwise stated, all strains and vectors were purchased from Invitrogen and Novagen and their characteristics are detailed in Table 3. Similarly, all chemicals were purchased from Sigma-Aldrich (St. Louis, MO, USA) or Aladdin (Shanghai, China). Antibiotics were purchased from Melonepharm (Dalian, China), unless otherwise indicated. Restriction enzymes and T4 DNA ligase were purchased from New England Biolabs (Hertfordshire, UK) or Takara (Dalian, China). Enzymes used for DNA amplification and kits used for RNA/plasmid/DNA isolation were purchased from Vazyme (Nanging, China). The plasmids pKD3, pKD46 and pCP20 used for gene disruption were acquired from the Yale E. coli Genetic Stock Center.

\section{Plant materials, RNA isolation, library preparation, sequencing, assembly and functional annotation}

A. decursiva material was collected from our medicinal botanical garden at China Pharmaceutical University. The plant was immediately frozen in liquid nitrogen and stored at $-80^{\circ} \mathrm{C}$ until use. Total RNA was isolated using TransZol Plant reagent (TransGen Biotech, Beijing, China) according to the user guidelines. After integrity and quality checks, the RNA was used as a template for cDNA amplification using SMARTerTM RACE Amplification Kit (Clontech Laboratories, Inc., Mountain View, CA, USA) and TruSeq Stranded mRNA Library Prep Kit
(Illumina). Subsequently, the cDNA was subjected to end-repair, phosphorylation and "A" base addition according to the library construction protocol. Sequencing, assembly and functional annotation methods were according to our previous report [23]. The RNA-seq data generated in this work have been deposited in the SRA (Sequence Read Archive) database under BioProject ID PRJNA360870.

\section{Characterization of genes in the umbelliferone pathway and CDNA cloning}

To identify the target nucleic acid sequences, a local BLAST search was conducted using the program of TBLASTN in Bioedit Sequence Alignment Editor according to the deep sequencing dataset of $A$. decursiva. For details, previously reported functionally identified protein sequences were extracted from NCBI and used for template for local homologous BLAST searches [25-27]. The template used in this work, the local BLAST results for each gene and their E-Values are listed in Table 1. Unigenes exhibiting the highest similarity were used to design primers for amplifying full-length cDNA from $A$. decursiva using SMARTer ${ }^{\text {ru }}$ RACE Amplification Kit [23]. The PCR products were cloned into the pMD19-T vector (Takara, Dalian, China) for DNA sequencing. After sequencing, the PCR fragments were joined reveal the open reading frames (ORFs). Finally, the candidates were re-amplified using gene-specific primers with the corresponding primers for construction of the expression vectors. All the primers used in this work are listed in Additional file 1: Table S3.

\section{Protein expression, purification and enzymatic reaction}

All of the genes were cloned into pET28a with an $\mathrm{N}$-terminal fusion histidine tag for expression and purification. Recombinant plasmids were first introduced into $E$. coli BL21 (DE3), and the bacteria were cultured in $200 \mathrm{~mL}$ Luria-Bertani medium at $37^{\circ} \mathrm{C}$ until the OD 600 reached 0.4-0.8. $100 \mu \mathrm{M}$ IPTG was added followed by overnight induction at $16^{\circ} \mathrm{C}$. For protein purification, the culture was centrifuged at $5000 \times \mathrm{g}$ for $10 \mathrm{~min}$ at $4{ }^{\circ} \mathrm{C}$. Then, the cells were re-suspended in buffer $\left(50 \mathrm{mM} \mathrm{NaH} \mathrm{NO}_{4}, 300 \mathrm{mM}\right.$ $\mathrm{NaCl}, \mathrm{pH}$ 8.0) and centrifuged again. After ultrasonication, the re-suspended cells were centrifuged at $15000 \times \mathrm{g}$ for 30 $\min$ at $4{ }^{\circ} \mathrm{C}$ to remove the cell debris. The supernatant was used for protein purification with a Ni-NTA affinity column and FPLC (ÄKTA, GE Healthcare Bio-Sciences) according to our previous study [25]. Finally, protein concentrations were determined using the Bradford kit (Jiancheng, Nanjing, China) according to the technical manual, and the samples were was stored at $-80^{\circ} \mathrm{C}$ until use. For enzymatic reactions, different proteins $(1 \mu \mathrm{g})$ were incubated with various substrates (approximately 1 $\mathrm{mM})$ at $37^{\circ} \mathrm{C}$ for $30 \mathrm{~min}(100 \mathrm{mM}$ Tris- $\mathrm{HCl} \mathrm{pH} \mathrm{8.0)}$. When necessary, $5 \mathrm{mM}$ ATP, $5 \mathrm{mM} \mathrm{MgCl}_{2}$, and 0.3 
$\mathrm{mM}$ CoA were added to the reaction system according to our previous reports $[25,26]$.

\section{Reconstruction of the metabolic pathway}

According to the metabolic pathway involved in the biosynthesis of the umbelliferone, gene knockout was first employed to optimize the metabolic route to construct a high yield platform using the classical $\lambda$ Red homologous recombination method [49]. Specifically, pheA, trpE, tyrR were knocked out, singularly or in combination, to produce tyrosine (Table 3) [34]. All primers used in this work are listed in Additional file 1: Table S3.

\section{Construction of expression vectors}

The plasmid used for precursor supply was constructed in pRSFDuet-1. First, six genes ( $t k t A$, aroG, tyrA, aroB, aroE, aroK) were $\mathrm{PCR}$ amplified and cloned into PMD19-T for overlap or site-specific mutagenesis. The genes were constructed into pRSFDuet-1 by T4 DNA ligase or overlap PCR when necessary. TktA was cloned into pRSFDuet-1 directly between $5^{\prime}$-Nco I and Sac I-3' sites to produce pRSFDuet$t k t A$ (pRSF-1). The aroE and aroK first pieced together with the T7 and RBS sequences to generate T7-RBS-aroE and T7-RBS-aroK and then overlapped with $\operatorname{aroB}$ to generate aroB-T7-RBS-aroE -T7-RBS-aroK. The overlapping fragment was ligated to pRSF-1 to generate pRSFDuet-tktA-aro$B$-aroE-aroK (pRSF-2) with 5'-EcoR V and Avr II-3'. For aroG and tyrA construction, the genes were first mutated to generate feedback-inhibition-resistant (fbr) genes aroG $G^{f b r}$ and $t_{y} A^{f b r}$ using KOD-plus-neo (Toyobo, Toyobo Life Science Department). Subsequently, $\operatorname{aroG}^{\mathrm{fbr}}$ and $\operatorname{tyr}^{\mathrm{fbr}}{ }^{\mathrm{fb}}$ were joined with T7 and RBS sequences to generate T7-RBS$\operatorname{aro}^{f b r}$-T7-RBS-tyrA $A^{f b r}$, and the fragment was ligated to pRSF-2 to yield pRSFDuet- $t k t A$-aro $G^{f b r}$-tyr $A^{f b r}$-aroB-aroE-ar $o K$ (pRSF) with 5'-Sac I and Not I-3'.

The compound synthetic pathway consists of three enzymes: RgTAL, Ad4CL and AdC2'H. As it described above, TAL and 4CL were directly synthesized and cloned into the multi-cloning site of pCDFDuet-1 at $5^{\prime}$-Nco I/BamH I-3' and $5^{\prime}$-Nde I/Kpn I-3' to yield pCDFDuet-TAL and pCDFDuet-TAL-4CL (pCDF-1 and pCDF-2), respectively. Similarly, $\mathrm{C} 2$ 'H was inserted into the second multi-cloning site of pCDF-2 at $5^{\prime}-\mathrm{Kpn} \mathrm{I} /$ Xho I-3' (pCDF). All primers used to construct expression vectors are listed in Additional file 1: Table S3.

\section{Virtual screening and site-specific mutagenesis of $4 \mathrm{CL}$}

To select a candidate $4 \mathrm{CL}$ for efficiently producing umbelliferone, different sources of 4CL were first virtually screened and then further mutated by site-specific mutagenesis. Approximately 18 4CLs from different resources were first selected (Additional file 1: Table S4), and, all structures except for Arabidopsis thaliana 4CL1 (At4CL1) and Pt4CL were predicted using SWISS-MODEL [50] because the crystal structures of At4CL1 and Pt4CL have been resolved and are available in the Protein Data Bank (PDB, 3TSY and 3NI2/3A9V) [41, 51]. The structures of adenosine 5 '-coumaroyl phosphate and proteins were prepared with the LigPrep module and Protein Preparation Wizard module (Schrödinger 2014, LLC, New York, NY) [52]. The core pattern was adopted considering that adenosine $5^{\prime}$-coumaroyl phosphate is somewhat large and contains many rotatable bonds. That is, the binding mode of 3NI2 (Pt4CL and adenosine 5'-(3-(4-hydroxyphenyl) propyl) phosphate) was used as a reference for docking adenosine $5^{\prime}$-coumaroyl phosphate to all 18 proteins (Additional file 1: Table S4). As the structural differences among these enzymes were also taken into account, a rather large tolerance value of $5 \AA$ was adopted when docking. Docking was carried out using the Glide module (Glide, Schrödinger) and the results were selected and refined by the Refine Protein-Ligand Complex program in the Prime module (Prime, Schrödinger) (Additional file 1: Figure S2) [47]. Binding energies were estimated through the $\mathrm{mm} / \mathrm{gbsa}$ method in Prime, and the 18 enzymes were sorted according to estimated binding energies. Finally, the candidate $4 \mathrm{CL}$ was cloned into pCDF-1 for fermentation. To further improve the yield of the umbelliferone, site-specific mutagenesis was conducted to produce a series of mutants. Firstly, according to the protein structure of Pt4CL and the directed evolution results of Le4CL, key amino acid residues which may play a better performance in $4 \mathrm{CL}$ activity was selected [40,41]. For instance, V186, F239, Q274 in Le4CL and Y236 in Pt4CL. Then sequence alignment was conducted among Pc4CL1, Le4CL and Pt4CL to find the amino acid residues in Pc4CL corresponding to V186, F239, Q274 in Le4CL and Y236 in Pt4CL [40, 41]. Multiple sequence alignment was performed using DNAMAN (Lynnon Corp., Pointe-Claire, QC, Canada) and the protein accession numbers used in sequence alignment are X13324.1, NP_001333770.1 and AY043495.1 for Pc4CL1, Le4CL and Pt4CL, respectively (Additional file 1: Figure S3) [40, 41]. At last, candidate mutations were generated according to the results in Le4CL and Pt4CL. For instance, in Le4CL, V186G and F239S could improve the activity of Le4CL towards $p$-coumaric acid. In our target Pc4CL, the corresponding mutations of V184G, Q272H, F267 L, and so on, were generated. All primers used are listed in Additional file 1: Table S3.

\section{Culture and biotransformation conditions and experimental design}

For recombinant plasmid construction, gene knockout and seed culture, LB medium $(10 \mathrm{~g} / \mathrm{L}$ tryptone, $5 \mathrm{~g} / \mathrm{L}$ yeast extract and $10 \mathrm{~g} / \mathrm{L} \mathrm{NaCl}$ ) with various concentrations of antibiotics (ampicillin $100 \mathrm{mg} / \mathrm{L}$, chloramphenicol $34 \mathrm{mg} / \mathrm{L}$, kanamycin $50 \mathrm{mg} / \mathrm{L}$ and streptomycin 50 
$\mathrm{mg} / \mathrm{L}$ ) as used. For shake flask fermentation, the seed culture was incubated overnight in LB medium, and then $0.25 \mathrm{~mL}$ of the seeds were inoculated into a triangle flask containing $25 \mathrm{~mL}$ medium. $\mathrm{FeSO}_{4}, \mathrm{FeCl}_{3}, \mathrm{CaCl}_{2}, \mathrm{MgCl}_{2}$, $\mathrm{ZnSO}_{4}, \mathrm{CuSO}_{4}, \mathrm{MnSO}_{4}, \mathrm{CoCl}_{2}, \mathrm{NiCl}_{2}$, $\mathrm{LiAc}$ and $\mathrm{Na}_{2} \mathrm{MoO}_{4}$ at concentrations of 50,100 and $500 \mathrm{mg} / \mathrm{L}$ were added to investigate the effects of ions on product yield. In addition, the concentration (IPTG and lactose at concentrations of 1 , $10,100,1000 \mu \mathrm{M})$, temperature $\left(15,20,25,30,35^{\circ} \mathrm{C}\right)$ and time $(5,10,15,20,25 \mathrm{~h})$ of induction were investigated. All medium and fermentation conditions were optimized using M9 minimal medium with an induction temperature of $16^{\circ} \mathrm{C}$ and a transformation temperature of $35^{\circ} \mathrm{C}$.

\section{High performance liquid chromatography (HPLC) and yield analysis}

Reversed phase HPLC using C18 column (XDB-C18, 5 $\mathrm{mm}$; Agilent, USA) was conducted to analyze candidate compounds at a flow of $1 \mathrm{~mL} / \mathrm{min}$. For sample preparation, the fermentation broth was collected by centrifugation and the supernatant was then injected for analysis. For PAL and $\mathrm{C} 4 \mathrm{H}$ analysis, $42 \%$ acetonitrile isocratic was used for approximately $15 \mathrm{~min}$. For $4 \mathrm{CL}$ and $\mathrm{C}^{\prime} \mathrm{H}$ analysis, the solvent gradient conditions A $\left(\mathrm{H}_{2} \mathrm{O}\right)$ : $\mathrm{B}$ (methanol; v/v) were as follows: $0 \mathrm{~min}, 95: 5 ; 5 \mathrm{~min}, 90: 10 ; 15 \mathrm{~min}, 40: 60$; $20 \mathrm{~min}, 10: 90$. For umbelliferone analysis, the solvent gradient conditions A $\left(\mathrm{H}_{2} \mathrm{O}\right)$ : B (methanol; v/v) were as follows: $0 \mathrm{~min}, 95: 5 ; 5 \mathrm{~min}, 40: 60 ; 15 \mathrm{~min}$, 5:95.

\section{Additional file}

Additional file 1: Figure S1 Experimental design of construction of a tyrosine high-producing platform. The overexpressed genes in this work are marked with red arrow and the knocked genes are marked with brown. TAL, tyrosine ammonia lyase; $4 \mathrm{CL}$, 4-coumarate: coenzyme A ligase; $\mathrm{C2}$ 'H, $p$-coumaroyl CoA 2'-hydroxylase; E-4-P, erythrose 4-phosphate; CHA, chorismate; DAHP, 3-deoxy-arabinoheptulosonate-7-phosphate; tktA transketolase; aroG $G^{\text {fbr }}$, feedback resistant mutant DAHP synthase; tyr $A^{\text {fbr }}$, feedback resistant mutant chorismate mutase/prephenate dehydrogenase ; aroB, dehydroquinate synthase; aroE, shikimate dehydrogenase; aroK, shikimate kinase I; tyrR, transcriptional regulatory protein; pheA, prephenate dehydratase; trpE, anthranilate synthase. Figure S2 Homology modeling and docking of PC4CL with adenosine 5'-coumaroyl phosphate. The amino acid main chains are displayed in ribbon and the main amino acids are marked with globular and stick. Figure S3 Sequence alignment of Pc4CL with Le4CL and Pt4CL. Multiple sequence alignment was performed using DNAMAN and the protein accession numbers used in sequence alignment are X13324.1, NP_001333770.1 and AY043495.1 for PC4CL1, Le4CL and Pt4CL, respectively. The selected mutation sites are marked with black squares. Table S1 Effects of different ions on the production of umbelliferone. Table S2 Effects of fermentation conditions on the production of umbelliferone. Table $\mathbf{S} \mathbf{3}$ Primers used in this study. Table S4 Candidate 4CLs used for virtual screening. (DOCX 2084 kb)

\section{Author' contributions}

YCZ designed and performed the majority of the experimental work and wrote the manuscript. JLW, WCH and XYJ performed the majority of the molecular cloning and functional verification. CLH was involved in the virtual screening and site-specific mutagenesis of $4 C L$. XYJ, JLW and $J L$ helped in writing the manuscript. LYK was responsible for the original concept and supervised the work. All authors read and approved the final manuscript.

\section{Funding}

This project was funded by the China Postdoctoral Science Foundation (2016 M601922, 2018 T110577), the National Natural Science Foundation of China (81703637) and the Natural Science Fund in Jiangsu Province (BK20170736). This research was also supported by the Program for Changjiang Scholars and Innovative Research Team in University (IRT_15R63), 111 Project from the Ministry of Education of China and the State Administration of Foreign Export Affairs of China (B18056).

Availability of data and materials

All data generated or analyzed during this study are included in this published article (and its supplementary information files).

Ethics approval and consent to participate Not applicable.

Consent for publication

Not applicable.

\section{Competing interests}

The authors declare that they have no competing interests.

\section{Publisher's Note}

Springer Nature remains neutral with regard to jurisdictional claims in published maps and institutional affiliations.

Received: 22 February 2019 Accepted: 30 April 2019

Published online: 22 May 2019

\section{References}

1. Ojala T, Remes S, Haansuu P, Vuorela H, Hiltunen R, Haahtela K, Vuorela P. Antimicrobial activity of some coumarin containing herbal plants growing in Finland. J Ethnopharmacol. 2000;73:299-305.

2. Marienhagen J, Bott M. Metabolic engineering of microorganisms for the synthesis of plant natural products. J Biotechnol. 2013;163:166-78.

3. Bourgaud F, Hehn A, Larbat R, Doerper S, Gontier E, Kellner S, Matern U. Biosynthesis of coumarins in plants: a major pathway still to be unravelled for cytochrome P450 enzymes. Phytochem Rev. 2006;5:293-308.

4. Musa MA, Cooperwood JS, Khan MOF. A review of coumarin derivatives in pharmacotherapy of breast cancer. Curr Med Chem. 2008:15:2664-79.

5. Clere N, Faure S, Martinez MC, Andriantsitohaina R. Anticancer properties of flavonoids: roles in various stages of carcinogenesis. Cardiovasc Hematol Agents Med Chem. 2011;9:62-77.

6. Gresele P, Cerletti C, Guglielmini G, Pignatelli P, De GG, Violi F. Effects of resveratrol and other wine polyphenols on vascular function: an update. J Nutr Biochem. 2011;22:201-11.

7. Commission, C. P. Pharmacopoeia of the People's republic of China, vol. 1. Beijing: People's Medical Publishing House; 2010.

8. Hou Z, Luo J, Wang J, Kong L. Separation of minor coumarins from Peucedanum praeruptorum using HSCCC and preparative HPLC guided by HPLC/MS. Sep Purif Technol. 2010;75:132-7.

9. Ling-Yi K, Yi L, Zhi-Da M, Xian L, Ting-Ru Z. Coumarins from Peucedanum praeruptorum. Phytochemistry. 1996:41:1423-6.

10. Feher M, Schmidt JM. Property distributions: differences between drugs, natural products, and molecules from combinatorial chemistry. Cheminform. 2003;34(17):218.

11. Galanie S, Thodey K, Trenchard IJ, Interrante MF, Smolke CD. Complete biosynthesis of opioids in yeast. Science. 2015;349:1095-100.

12. Milke L, Aschenbrenner J, Marienhagen J, Kallscheuer N. Production of plant-derived polyphenols in microorganisms: current state and perspectives. Appl Microbiol Biotechnol. 2018;102(4):1575-85.

13. Xu P, Bhan N, Koffas MA. Engineering plant metabolism into microbes: from systems biology to synthetic biology. Curr Opin Biotechnol. 2013;24(2):291-9. 
14. Zhao Q, Zhang Y, Wang G, Hill L, Weng JK, Chen XY, Xue H, Martin C. A specialized flavone biosynthetic pathway has evolved in the medicinal plant, Scutellaria baicalensis. Sci Adv. 2016;2:e1501780.

15. Tian X, Ruan JX, Huang JQ, Yang CQ, Fang X, Chen ZW, Hong H, Wang LJ, Mao YB, Lu S. Characterization of gossypol biosynthetic pathway. P Natl Acad Sci USA. 2018;115:201805085.

16. Hawkins KM, Smolke CD. Production of benzylisoquinoline alkaloids in Saccharomyces cerevisiae. Nat Chem Biol. 2008;4:564-73.

17. Horinouchi S. Combinatorial biosynthesis of plant medicinal polyketides by microorganisms. Curr Opin Chem Biol. 2009;13:197-204.

18. Lee SY, Kim HU. Systems strategies for developing industrial microbial strains. Nat Biotechnol. 2015;33:1061-72.

19. Bhan N, Xu P, Koffas MA. Pathway and protein engineering approaches to produce novel and commodity small molecules. Curr Opin Biotechnol. 2013;24(6):1137-43.

20. Ehrenworth AM, Peraltayahya P. Accelerating the semisynthesis of alkaloidbased drugs through metabolic engineering. Nat Chem Biol. 2017;13:249.

21. Santos CN, Koffas M, Stephanopoulos G. Optimization of a heterologous pathway for the production of flavonoids from glucose. Metab Eng. 2011;13:392.

22. Hata K, Sano K. Studies on coumarins FR.Om the root of Angelica decursiva FR et SAV. I. the structure of decursin and decursidin. Yakugaku Zasshi. 1969;89:549

23. Zhao Y, Liu T, Luo J, Oian Z, Sheng X, Chao H, Xu J, Chen M, Chen Y, Kong L. Integration of a Decrescent transcriptome and metabolomics dataset of Peucedanum praeruptorum to investigate the CYP450 and MDR genes involved in Coumarins biosynthesis and transport. Front Plant Sci. 2015;6:163-6.

24. Park JH, Park NI, Xu H, Park SU. Cloning and characterization of phenylalanine ammonia-lyase and cinnamate 4-hydroxylase and pyranocoumarin biosynthesis in Angelica gigas. J Nat Prod. 2010;73:1394-7.

25. Yao R, Zhao Y, Liu T, Huang C, Xu S, Sui Z, Luo J, Kong L. Identification and functional characterization of a p-coumaroyl CoA 2'-hydroxylase involved in the biosynthesis of coumarin skeleton from Peucedanum praeruptorum Dunn. Plant Mol Biol. 2017;95:199-213.

26. Liu T, Yao R, Zhao Y, Xu S, Huang C, Luo J, Kong L. Cloning, Functional Characterization and Site-Directed Mutagenesis of 4-Coumarate: Coenzyme A Ligase (4CL) Involved in Coumarin Biosynthesis in Peucedanum praeruptorum Dunn. Front Plant Sci. 2017:8:549.

27. Logemann E, Parniske M, Hahlbrock K. Modes of expression and common structural features of the complete phenylalanine ammonia-lyase gene family in parsley. Proc Natl Acad Sci U S A. 1995:92:5905-9.

28. Lv Y, Edwards H, Zhou J, Xu P. Combining $26 \mathrm{~s}$ rDNA and the Cre-loxP system for iterative gene integration and efficient marker curation in Yarrowia lipolytica. ACS Synth Biol. 2019;8:568-76.

29. Zhao Y, Wang N, Zeng Z, Xu S, Huang C, Wang W, Liu T, Luo J, Kong L. Cloning, Functional Characterization, and Catalytic Mechanism of a Bergaptol O-Methyltransferase from Peucedanum praeruptorum Dunn. Front Plant Sci. 2016;7:722.

30. Munakata R, Olry A, Karamat F, Courdavault V, Sugiyama A, Date Y, Krieger C, Silie P, Foureau E, Papon N. Molecular evolution of parsnip (Pastinaca sativa) membrane-bound prenyltransferases for linear and/or angular furanocoumarin biosynthesis. New Phytol. 2016;211:332-44.

31. Luan LC, Pandey RP, Lim HN, Jung HJ, Thuan NH, Kim TS, Sohng JK. Synthesis of umbelliferone derivatives in Escherichia coli and their biological activities. J Biol Eng. 2017;11:15

32. Yang SM, Shim GY, Kim BG, Ahn JH. Biological synthesis of coumarins in Escherichia coli. Microb Cell Factories. 2015;14:1-12.

33. Duan L, Ding W, Liu X, Cheng X, Cai J, Hua E, Jiang H. Biosynthesis and engineering of kaempferol in Saccharomyces cerevisiae. Microb Cell Factories. 2017;16:165

34. Yao YF, Wang CS, Qiao J, Zhao GR. Metabolic engineering of Escherichia coli for production of salvianic acid a via an artificial biosynthetic pathway. Metab Eng. 2013;19:79.

35. Lütkeeversloh T, Stephanopoulos G. Combinatorial pathway analysis for improved L-tyrosine production in Escherichia coli: identification of enzymatic bottlenecks by systematic gene overexpression. Metab Eng. 2008;10:69-77.

36. Juminaga D, Baidoo EEK, Redding-Johanson AM, Batth TS, Burd H, Mukhopadhyay A, Petzold CJ, Keasling JD. Modular engineering of Ltyrosine production in Escherichia coli. Appl Environ Microbiol. 2012;78: 89-98.

37. Pittard J, Camakaris H, Yang J. The TyrR regulon. Mol Microbiol. 2005;55:16-26.
38. Lütke-Eversloh T, Stephanopoulos G. Feedback inhibition of chorismate mutase/prephenate dehydrogenase (TyrA) of Escherichia coli: generation and characterization of tyrosine-insensitive mutants. Appl Environ Microbiol. 2005:71:7224-8

39. Vannelli T, Wei WQ, Sweigard J, Gatenby AA, Sariaslani FS. Production of $p$ -hydroxycinnamic acid from glucose in Saccharomyces cerevisiae and Escherichia coli by expression of heterologous genes from plants and fungi. Metab Eng. 2007;9:142

40. Alberstein M, Eisenstein M, Abeliovich H. Removing allosteric feedback inhibition of tomato 4-coumarate: CoA ligase by directed evolution. Plant J. 2012;69:57-69.

41. Hu Y, Gai $Y$, Yin L, Wang $X$, Feng C, Feng L, Li D, Jiang XN, Wang DC. Crystal structures of a Populus tomentosa 4-Coumarate:CoA ligase shed light on its enzymatic mechanisms. Plant Cell. 2010;22:3093-104.

42. Li H, Qiu T, Gao D, Cao Y. Medium optimization for production of gammaaminobutyric acid by Lactobacillus brevis NCL912. Amino Acids. 2010;38:1439.

43. Mahmoud AM, Germoush MO, Alotaibi MF, Hussein OE. Possible involvement of Nrf2 and PPARy up-regulation in the protective effect of umbelliferone against cyclophosphamide-induced hepatotoxicity. Biomed Pharmacother. 2017:86:297-306.

44. Luzi F, Puglia D, Dominici F, Fortunati E, Giovanale G, Balestra GM, Torre L. Effect of gallic acid and umbelliferone on thermal, mechanical, antioxidant and antimicrobial properties of poly (vinyl alcohol-co-ethylene) films. Polym Degrad Stab. 2018:152:162-76.

45. Chen X, Li M, Zhou L, Shen W, Algasan G, Fan Y, Wang Z. Metabolic engineering of Escherichia coli for improving shikimate synthesis from glucose. Bioresource Techn. 2014;166:64-71.

46. Lin Y, Sun X, Yuan Q, Yan Y. Combinatorial biosynthesis of plant-specific coumarins in bacteria. Metab Eng. 2013;18:69-77.

47. Friesner RA, Murphy RB, Repasky MP, Frye LL, Greenwood JR, Halgren TA, Sanschagrin PC, Mainz DT. Extra precision glide: docking and scoring incorporating a model of hydrophobic enclosure for protein-ligand complexes. J Med Chem. 2006:49:6177.

48. Patnaik R, Zolandz RR, Green DA, Kraynie DF. L-tyrosine production by recombinant Escherichia coli: fermentation optimization and recovery. Biotechnol Bioeng. 2008;99:741-52.

49. Datsenko KA, Wanner BL. One-step inactivation of chromosomal genes in Escherichia coli K-12 using PCR products. P Natl Acad Sci USA. 2000;97:6640.

50. Biasini M, Bienert S, Waterhouse A, Arnold K, Studer G, Schmidt T, Kiefer F, Gallo CT, Bertoni M, Bordoli L. SWISS-MODEL: modelling protein tertiary and quaternary structure using evolutionary information. Nucleic Acids Res. 2014;42:W252.

51. Wang $Y, Y i H$, Wang M, Yu O, Jez JM. Structural and kinetic analysis of the unnatural fusion protein 4-Coumaroyl-CoA ligase::stilbene synthase. J Am Chem Soc. 2011;133:20684

52. Sastry GM, Adzhigirey M, Day T, Annabhimoju R, Sherman W. Protein and ligand preparation: parameters, protocols, and influence on virtual screening enrichments. J Compuet Aid Mol Des. 2013;27:221.

Ready to submit your research? Choose BMC and benefit from:

- fast, convenient online submission

- thorough peer review by experienced researchers in your field

- rapid publication on acceptance

- support for research data, including large and complex data types

- gold Open Access which fosters wider collaboration and increased citations

- maximum visibility for your research: over $100 \mathrm{M}$ website views per year

At $\mathrm{BMC}$, research is always in progress.

Learn more biomedcentral.com/submission 